\title{
DOS MUJERES, DOS VOTOS, DOS PELÍCULAS. LAS BOSTONIANAS Y EL CASO WINSLOW
}

\author{
Mónica Barrientos Bueno \\ Universidad de Sevilla
}

\begin{abstract}
El sufragismo, una de las principales batallas de la mujer en sus conquista de igualdad social con el hombre, no se prodiga demasiado en el cine'; además, entre los escasos ejemplos, ha predominado una imagen grotesca con la que se parodia a las activistas del movimiento, mostradas como unas alocadas fanáticas: "las sufragistas, las mesmeristas y las abolicionistas del siglo XIX resultan manifestaciones — con la perspectiva del siglo XX- de tipologías excéntricas" (García, 1994: 57). Tomemos como punto de partida dos comedias, vehículo perfecto donde tales extremos encajan de forma natural, una musical: Mary Poppins (R. Stevenson, 1963) y otra un atípico western: La batalla de las colinas del whisky (The hallelujah trail, J. Sturges, 1965). En la primera, la mayor parte de las apariciones de la señora Banks (Glynis Johns) está vinculada a sus actividades sufragistas, las cuales vive de forma agitada²; luce, cruzando su pecho, una banda donde reza Votes for women, la cual manda guardar a sus sirvientas dada la escasa acogida de su marido hacia sus ideas políticas. Las actividades a las que la madre de Jane y Michael está vinculada tienen carácter violento 3 . El personaje, volcado al completo en ello, carece de tiempo para sus hijos, tarea que intenta encargar a otros personajes; de esta manera es trazada como "una mala madre" que prefiere el sufragismo al hogar. Finalmente, la señora Banks volverá al hogar y recuperará a sus hijos:
\end{abstract}

1 Por otra parte, como el documental Suffragettes in the Silent Cinema (Kay Sloan, 2003) demuestra, es un camino de ida y vuelta: las sufragistas estadounidenses aprovecharon las posibilidades del cine como arma ideológica.

2 La canción con la que se presenta es elocuente sobre sus actividades beligerantes ("We're cleary soldiers in petticoats / and daughters crusaders for women's votes [...] We're fighting for our rights militantly"). Es más explícita con respecto a algunos detalles de la situación del sufragismo en Gran Bretaña que la versión en castellano (por ejemplo, en el original se menciona a una de las líderes más relevantes, la señora Pankhurst).

3 Por ejemplo una de sus compañeras está en prisión por haberse acercado con sus reivindicaciones al primer ministro o, en otra ocasión, la propia señora Banks lleva huevos podridos en el bolso para lanzárselos al dirigente del país. 
la cometa arreglada con papeles de periódico contará con una cola que impulse su vuelo: la cinta donde reza Votes for women cruzará el cielo de Londres ${ }^{4}$. En el segundo ejemplo, La batalla de las colinas del whisky, Cora Massingale (Lee Remick) es una abanderada del feminismo y prohibicionista ${ }^{5}$, que declara cómo su movimiento no se considera político. En su cruzada contra el alcohol, el grupo de la que es líder buscará interceptar y destruir un convoy de destilados que se dirige a Denver, aunque encontrará la oposición de la escolta militar del coronel Gearhart, la población masculina de la ciudad de destino, los indios, el dueño del envío y los carreteros irlandeses con reivindicaciones laborales. Las feministas se muestran con una fuerza arrolladora que emplea todas sus armas para conseguir sus propósitos, aunque finalmente la señora Massingale sucumbe al alcohol "en dosis medicinales" y al matrimonio con el coronel (llega a él doblemente viuda).

En las páginas siguientes se propone un acercamiento al sufragismo en un entorno más dramático, con dos adaptaciones cinematográficas de sendas obras relevantes de este ámbito en la literatura: la realizada por James Ivory en 1984 sobre la novela Las bostonianas, de Henry James y la de David Mamet, de 1999, a partir de la pieza teatral The Winslow boy, de Terence Rattigan.

\section{UNA MUJER, OLIVE CHANCELLOR; UNA PELÍCULA, LAS BOSTONIANAS}

Olive Chancellor es uno de los personajes femeninos más interesantes de la literatura de Henry James ${ }^{6}$; bajo su capa de activista feminista ${ }^{7}$ en pos del voto para las mujeres esconde una dama de trasfondo amargo, cuya sexualidad se tiñe de reprimido lesbianismo (en su relación con Verena) y repulsión hacia los hombres (especialmente en lo que concierne y representa su primo, Basil Ransom) ${ }^{8}$. El film de Ivory aunque explota los aspectos más melodramáticos del texto original", "es una respuesta necesaria a un siglo de lecturas críticas que han visto la novela como un ataque a las mujeres y el lesbianismo" (Sorensen, 1997: 231). Su fecha de producción no es separable del contexto político de los años ochenta: trae temas

4 Este carácter conservador del final casa a la perfección con el ideario de la productora: Disney.

5 En EE.UU. estuvieron íntimamente ligados varios movimientos reformistas como el abolicionista, el prohibicionista y el sufragismo: "cualquiera que fuese la verdadera relación entre la borrachera y el voto para la mujer, las personas interesadas en el consumo de alcohol [...] llegaron a la conclusión de que el "voto para la mujer" era sinónimo de prohibición para el hombre" (Lloyd, 1970:29). De hecho, en la reunión inicial de las seguidoras de Cora Massingale en el fuerte, pueden verse pancartas donde se lee Gin is sin, Women remake men, Whiskey poisons the soul, Alcohol is man's downfall, If you love your daughter, drink water...

6 Las protagonistas, Olive y Verena, inauguran en la trayectoria del escritor su exploración del universo femenino más allá de la vida hogareña que busca una liberación en el mundo exterior. Por otra parte, MerchantIvory no es la primera vez que se acerca al universo de Henry James en la gran pantalla con Las bostonianas, antes lo había hecho con Los europeos (The Europeans, 1979) y posteriormente también con La copa dorada (The golden bowl, 2000).

7 La novela se inspira en hechos históricos del momento, relacionados con la emergencia de los movimientos feministas, recopilados por Henry James, así como fuentes literarias: "En Las bostonianas se destilan y escrutan veinte años de actividades feministas por parte del escritor" (DeSaussure, 1979: 580).

8 "Olive es un clásico ejemplo de sublimada invertida; su impulso sexual se ha convertido en odio por los hombres y en ansia de poder" (Grenier, 1984: 62).

9 "El film se convierte más en una variación sobre el original que una transcripción exacta" (Long, 1984: 75). 
de género y sexualidad a la gran pantalla y, por tanto, tiene potencial para contrarrestar la ola conservadora que las elecciones en Estados Unidos de principios de la década confirmaron $^{10}$ (Person, 2001: 102).

Olive (Vanessa Redgrave), atraída por la joven Verena Tarrant (Madeleine Potter), extraordinariamente capacitada para la oratoria, decide ponerla bajo su protección, instruirla y pulir su don para servir a la causa feminista; así consigue que ella también se consagre al movimiento. Sin embargo, su atractivo no pasa por alto para Basil Ransom (Christopher Reeve), un abogado sureño cuya ideología está en la antípoda de ellas pero que se enamora de Verena. De esta manera, el film de Ivory opta por resaltar la faceta romántica, un triángulo amoroso donde emerge una batalla entre Basil y Olive por la posesión de la señorita Tarrant. Es una lucha a varios niveles representada por opuestos 11: "un derrotado pero aún viril Sur contra un santurrón Boston. Conservadurismo contra reformismo. Un pobre luchador contra una rica idealista. Masculino contra femenino. Sexo contra virginidad. Heterosexualidad contra lesbianismo (sublimado)" (Grenier, 1984: 62).

Particularmente interesante es el retrato de Basil como héroe romántico que salva a su amada de la esclavitud mental a la que la tiene sometida la absorbente Olive; tal y como el propio director lo expresa, "ella está en brazos de Supermán" (Long, 2005:163)12, en alusión directa al papel que hizo conocido al actor Christopher Reeve, el cual ya había interpretado en tres ocasiones cuando encarna a Ransom. No puede pasarse por alto el rol de masculinidad que este actor representa firmemente en la cultura audiovisual del momento, aspecto que pesó en su elección para el papel y destacado por el film: "cuando fija sus oscuros e hipnóticos ojos sobre Verena, no se tiene duda de que la desea no para lo público sino para lo privado" (Long, 1985: 77). En contrapartida, Verena es presentada visualmente como una muñeca, peinada con unos coquetos tirabuzones, lo que enfatiza su aspecto de genuina inocencia femenina, inexperimentada y de perfil maleable por parte de quien se encuentre a su lado (sea Olive o Basil); puede achacársele, quizás, falta de suficiente atractivo y magnetismo como atraer tanto a Ransom como a Olive. Al respecto, conviene señalar que, en sus conversaciones con Basil, expone algunas de las líneas fundamentales del feminismo del último tercio del XIX (inculcadas por Olive): la apertura de las universidades a las mujeres, las responsabilidades familiares no comprometen una carrera como activista de la causa y las mujeres deberían tener los mismos derechos, oportunidades y privilegios que los varones.

El intenso nexo entre Olive y Verena ${ }^{13}$ se aproxima a una lectura lésbica. Adair apunta que la película "atribuye a las sufragistas una dimensión amorosa propia, una fisicidad pare-

10 En relación a la primera presidencia de Ronald Reagan y los emergentes debates sobre los derechos de las mujeres, The Equal Rights Amendment (al que se oponía Reagan), la homosexualidad y los derechos del colectivo.

11 De la misma forma que sucede en la novela de Henry James con lo público y lo privado, el Norte y el Sur, la clase modesta y acomodada (Sorensen, 1997: 234).

12 En relación con ello, y en la interesante lectura que de la película, bajo la clave de Christopher Reeve como Supermán que realiza Leland S. Person, la película inevitablemente introduce un debate en el imaginario americano sobre derechos de igualdad para las mujeres, la situación de la homosexualidad y sus identidades. El film ayuda a expresar, como otras muestras del periodo, que algunos superhombres pueden restaurar en América un tono masculino a una generación feminizada (Person, 2001:122).

13 La convivencia de dos mujeres sin relación familiar alguna, bajo estas características, era conocida como "Boston marriages" ("matrimonio bostoniano"). 
cida a la de los lienzos de Courbet, que despoja el amor de Olive por Verena de cualquier tinte de lesbianismo en el sentido estricto" (cit. en Pearson, 2001: 110-111). Aunque no cruce la frontera del conocimiento carnal en la alcoba, la relación latente se manifiesta de muchas formas en la cinta, por ejemplo en el contacto físico que mantiene la pareja ${ }^{14}$; se introduce de esta forma un montaje de escenas que ilustran la creciente complicidad que se manifiesta en esta relación femenina. Olive toca a Verena de forma sugestiva a lo largo de la película, la abraza, fricciona sus pies, la besa suavemente en los labios... Son signos de cierto tipo de intimidad sexual que funcionan de forma tangencial; en otra ocasión, cuando están en Nueva York, Verena — tumbada en la cama, aportando así un elemento erótico ausente en esa escena en la novela - plantea a Olive su vínculo con el movimiento bajo la perspectiva del cortejo: ésta besa la mano de su compañera cuando duda de su compromiso, se abrazan y la escena termina con el sonido en off de un beso. Este sentido se refuerza con la balada Anabel Lee de Edgar Allan Poe, tarareada por Verena cuando se abrazan en la playa de Cape Cod: el suyo es un amor idealizado de extraordinaria intensidad.

La interpretación de Olive por parte de Vanessa Redgrave dota al personaje de una enorme carga de atractiva melancolía, "es el gran triunfo de la película [...] no es la repelente y neurótica Olive de la novela de James, sino que está claramente destrozada por un problema íntimo" (Long, 1984: 76). Sin embargo, en relación a su perfil sufragista, tiene especial relevancia uno de los cambios más evidentes realizados en la adaptación cinematográfica de la obra original de James: es el que respecta al final. En la novela la activista sube al escenario del Music Hall de Boston en lugar de Verena, quien ha huido con Ransom, para anunciar que ésta no comparecerá; es una experiencia que vive casi como si se tratase de un martirio, una humillación de la que será difícil recuperarse. Sin embargo, en la cinta llega al atril convencida de relevar a la joven oradora, con un discurso persuasivo en el que desvela la importancia de la lucha sufragista y feminista como cuestión social antes que individual: quizás el momento de la emancipación aún no ha llegado, sin embargo los ideales del movimiento son más que una ilusión ${ }^{15}$. Como Olive descubre su voz y poder de oratoria, el film nos mueve a identificarlo con la corriente en pos de los derechos de la mujer, pero además a sentir que la identidad de género y roles ha sido configurada de una forma más normal. Verena no era la voz apropiada del sufragismo ${ }^{16}$.

La "victoria" de Ransom sobre Olive, al ganar a Verena para el matrimonio, encaja en la historia del movimiento en relación a la época en la que se sitúan los hechos: el enemigo más poderoso del feminismo en Estados Unidos era el pensamiento reaccionario posterior a la Guerra de Secesión y el miedo al voto de la población negra, especialmente de las mujeres negras; ello es simbolizado por el sur, representado por Basil Ransom.

14 Referencias explícitas a la homosexualidad se encuentran en otro film de Ivory, Maurice (1987).

15 A propósito de ello, Ivory comenta que no deseaban dejar el mismo final de la novela, con Olive en estado de shock por el abandono de Verena y ésta llena de lágrimas mientras Ransom se la lleva (Long, 2005: 160), por ello se concierta un final que encaje con la corriente feminista de los años ochenta y el discurso de Olive compendie las ideas de la protagonista que se han ido desplegando a lo largo de la novela y que, hasta ese momento, no se han plasmado.

16 No fue bien acogido en los círculos feministas; el propio James Ivory apunta que "si haces una película como ésa ahora, nadie dirá una palabra sobre ella... siempre que promueva los derechos de la mujer [...] la mayoría de ellos están garantizados [en Norteamérica y Europa Occidental]. Todo ha sucedido muy rápido... desde 1984, cuando se estrenó Las bostonianas, hasta hoy" (Long, 2005: 164). 
Fuera del triángulo protagonista, al film de Ivory suele achacársele que, dado el marcado carácter satírico del original literario, muchos de los personajes secundarios al ser llevados a la pantalla hayan perdido ese aspecto ${ }^{17}$; un ejemplo son la señorita Birdseye (Jessica Tandy), una veterana militante convertida en una apacible y amable anciana y la doctora Prance (Linda Hunt), cuya autoconfianza en la mujer y dudas sobre la necesidad de un movimiento de derechos igualitarios en la novela son eludidas y sustituidas, en la pantalla, por una desatención hacia las palabras de Verena en sus oratorias y una complicidad ideológica con Ransom. La elección de Linda Hunt no está exenta de la carga de asexualidad de su personaje (Ivory enfatiza que ha optado por una profesión que exige un elevado precio personal) si pensamos en su papel anterior en el film de Peter Weir El año que vivimos peligrosamente (The year of living dangerously, 1983).

\section{UNA MUJER, KATHERINE WINSLOW; UNA PELÍCULA, EL CASO WINSLOW}

En El caso Winslow nos encontramos con un personaje, Catherine (Rebecca Pidgeon), militante sufragista en la Inglaterra eduardiana anterior a la I Guerra Mundial. Estamos ante la primera vez que David Mamet dirige un texto del que no es autor, concretamente se trata de la obra teatral en dos actos de Terence Rattigan ${ }^{18}$, atraído sin duda por cuestiones como el heroísmo y el abnegación ${ }^{19}$. Por el empeño del patriarca, Arthur (Nigel Hawthorne), y con el apoyo de su hija, Catherine (Rebecca Pidgeon), la familia Winslow se ve inmersa en un costoso proceso para exonerar al joven Ronnie, cadete de la Academia Militar de Osborn, de la acusación de robo de un giro postal y lavar el honor del apellido Winslow. Ello implicará un largo litigio con las instituciones, el Almirantazgo y la propia Corona. La firme posición por defender lo que consideran justo lleva a multitud de pequeños y grandes sacrificios ${ }^{20}$ : la salud de Arthur se deteriora al agravarse su artritis, las finanzas flaquean por los gastos del proceso (por ejemplo Dickie, el hijo mayor, deberá abandonar sus estudios en Oxford para trabajar en un banco) y Catherine, activa sufragista, se ve presionada por su prometido a romper su compromiso si la familia no ceja en su empeño dada la repercusión social que ha tomado el caso (anteriormente ha debido de renunciar a su dote por los problemas económicos que atraviesa la familia). De esta forma, el film encadena una serie de conflictos sociales y personales pasando a un segundo plano el caso en sí, convertido en insignificante ante la sacudida que produce en las vidas de los personajes. Para Mamet el asunto principal es cuándo una lucha por la justicia se convierte en una arrogante caza de rectitud personal; de hecho Arthur llega a preguntarse en qué punto debe detenerse en una batalla por un principio abstracto (French, 2001: 171-193).

17 Así se lo señala Robert Emmet Long en su libro de charlas con el director: "hay una exuberancia en los retratos satíricos de los reformadores de Boston en Henry James que han sido atenuados en nuestra película" (Long, 2005: 162).

18 Basado, a su vez, en un caso real acaecido en 1908, el Archer-Shee (para más detalles véase Rossi, 2001: 220-224).

19 Llevada al cine anteriormente en una producción británica de 1950 conocida como Pleito de honor (Anthony Asquith).

20 De hecho, un aspecto a destacar en el film de Mamet es que se centra en los efectos que todo ello tiene en la familia Winslow. 
Catherine se perfila así como un personaje en apariencia secundario pero relevante, tanto por su condición de sufragista —un elemento de enorme poder contextual aunque no queda únicamente en eso, como ahora veremos- así como por la atracción potencial que surge entre ella y Sir Robert Morton (Jeremy Northam) ${ }^{21}$, el prestigioso abogado contratado para defender el caso. Catherine — quien debe mucho a la delicadeza con la que Rebecca Pidgeon lo aborda- es secretaria de la sede de Londres Oeste del grupo en el que colabo$\mathrm{ra}^{22}$. Externamente se perfila a través de varios aspectos. Por ejemplo, en una de las escenas iniciales lleva un libro entre sus manos, The social evil and the social good, las memorias del sindicalista radical Len Rogers. Como su padre se encarga de apuntar, una mujer enamorada que va a comprometerse leería a Byron. Su futuro marido, John, conoce sus inclinaciones políticas y aún así piensa casarse con ella, lo que sorprende sobremanera a Grace, su madre, quien le llega a comentar lo poco apasionado de su comportamiento, a lo que Catherine responde: "¿Cómo se supone que tiene que comportarse una enamorada?". El esmerado diseño de producción introduce como elemento presente en su habitación un póster originalmente creado por la Artists' Suffrage League hacia 1914, Handicapped ${ }^{23}$. Igualmente, la joven luce un colgante con una piedra morada (color identificativo de las sufragistas en Gran Bretaña junto al verde y el blanco, tonos habituales en su vestuario).

En Catherine ${ }^{24}$ se reúne la lucha por los derechos públicos y políticos, ya no sólo como activista sufragista sino en su participación en el caso de su hermano. Enfrentada ideológicamente a Sir Robert Morton, quien no cree en el voto femenino, considera que éste busca más la repercusión y la publicidad, en su propio beneficio de promoción política, que sacar adelante la causa. Sir Robert, personaje que aparece avanzado ya el metraje, resulta esencial: aparentemente ha aceptado el caso por la publicidad que le reporta, aunque luego se sabrá que no ha sido así. Entre él y Catherine se establece una tensión sexual no resuelta, mantenida hasta el final que fibrila ante la duda de la joven por la sinceridad del letrado debido a su reputación conservadora ${ }^{25}$, aunque terminará apreciando su determinación en busca de lo justo, no de justicia, sino de lo justo, cediendo así a la verdad que encierra el abogado.

21 Se trata de un elemento insinuado en la obra de Rattigan pero que en el film de Mamet se enfatiza sutilmente; explota básicamente al final, cuando se despide de ella con un "¡Qué poco conoce a los hombres!" acompañado de una sonrisa cómplice y divertida.

22 En una conversación con Sir Robert Morton le aclara que "No soy una militante [...] no voy por ahí rompiendo cristales o echando ácido en los buzones". La aparición en la casa del personaje de la periodista vendría a ser una pausa o contrapunto humorístico; representa la figura de la mujer profesional e independiente, sin embargo se interesa poco por el objeto de su visita, el caso Winslow y el joven Ronnie, a favor de cuestiones más frívolas (pregunta por las cortinas); se muestra impaciente por marcharse y extremadamente fría.

23 La parte gráfica muestra a una mujer en un bote a remos luchando contra la embestida de una ola mientras que en la cresta de ésta navega un joven en una nave a vela sin ningún esfuerzo (en la lona está inscrito de forma clara "Votes"). El Artists' Suffrage League, creado en 1907, diseñaba banners para el National Union of Women's Suffrage Societies, producía postales y pancartas para facilitar sus campañas, estaba abierto a artistas profesionales mientras que el Atelier (creado en 1914) se surtía del trabajo de aficionados.

24 "Todas las mujeres por las que Mamet siente una atracción especial son seres que luchan por abrirse camino y, lo que es más importante, Mamet procura que lo hagan de forma nada idealizada, sin caer en la mujer sufrida, débil, de mera comparsa, a la que suele estar destinada la mujer (o su representación) en la mayoría de las películas comerciales" (Cagiga, 2007: 78).

25 Es curioso que Catherine acuse a Sir Robert de frialdad y ocultamiento de sus sentimientos cuando su madre dice lo mismo de ella. 
La subtrama amorosa presenta un enfrentamiento ideológico entre hombre y mujer, entre Catherine y Sir Robert, entre la mentalidad del XIX y la del XX, que hace salir a flote los rasgos deliberadamente modernos de la joven, asidua por ejemplo a fumar ${ }^{26}$ (como igualmente se ve en la escena en el parlamento, donde en la galería de damas otras disfrutan de un cigarrillo mientras los políticos debaten sobre si el caso Winslow versus Rex va a juicio). A propósito de esa estancia ${ }^{27}$, esa misma noche Sir Robert comenta con Catherine, al visitar la casa de los Winslow, cómo estaba impresionado por el sombrero que lucía por la mañana: "Me parece una equivocación absoluta que se le permita a una dama de sus inclinaciones políticas adornarse con semejante encanto femenino. Es pretender gozar de lo mejor de los dos mundos". Sin embargo, su sorpresa se incrementa al saber que las labores de Catherine en la sede sufragista no son remuneradas: "¡Santo Dios, cuántos sacrificios están dispuestas a hacer las mujeres por sus convicciones", evidente trasunto del ideario de la joven, dispuesta a inmolar lo necesario por sus creencias, ya se trate de lavar el honor de su hermano (renuncia así primero a su dote y posteriormente al matrimonio) o de defender sus ideas sufragistas.

Especialmente relevante es el papel de Arthur Winslow, ya no por su empeño en el asunto de Ronnie sino por ser un padre que apoya a sus hijos, incluida una sufragista, la nueva mujer, sin problemas y sobre todo con el estatus del que goza, banquero retirado: orgulloso de su familia, previsor y moderno ${ }^{28}$.

\section{BIBLIOGRAFÍA CITADA}

BIGSBY, Christopher, "David Mamet", en Christopher Bigsby (ed.), The Cambridge Companion to David Mamet, Cambridge, Cambridge UP, 2004, pp. 1-40.

BRAUN, Heather, "The 1990's", en Christopher Bigsby (ed.), The Cambridge Companion to David Mamet, Cambridge, Cambridge UP, 2004, pp. 103-123.

CAGIGA, Nacho, David Mamet. La desvelada naturaleza de la verdad, Madrid, Akal, 2007.

CASAS, Quim, "David Mamet. El juego de la representación", Dirigido por, 284 (1999), pp. 44-53.

"Una austera pieza de cámara", Dirigido por, 284 (1999), pp. 54-55.

DeSAUSSURE DAVIS, Sara, "Feminist sources in The Bostonians", American Literature, 50.4 (1979), pp. 570-587.

FRENCH, Philip, "David Mamet and film", en Christopher Bigsby (ed.), The Cambridge Companion to David Mamet, Cambridge, Cambridge UP, 2004, pp. 171-193.

GARCÍA BRUSCO, Carlos, "James Ivory. Un transterrado cultural", Dirigido por, 222 (1994), PP. 50-65.

GRAHAM, Renée, "Mamet costumbrista", en Leslie Kane, Conversaciones con David Mamet, Barcelona, Alba, 2005, pp. 287-292.

GRENIER, Richard, "The Bostonians inside out", Commentary, 78.4 (1984), pp. 60-65.

IVORY, James, "The trouble with Olive. Divine madness in Massachussetts", Sight and Sound, 54.2 (1985), pp. 95-100.

26 En aquella época, fumar era un símbolo del pensamiento moderno además de una osadía.

27 Se muestra cómo Catherine, como otras damas, debía mostrar su bolso y pertenencias antes de acceder (podían llevar bombas, ácido, pintura... para lanzar, estrategia habitual de las sufragistas más beligerantes).

28 David Mamet, en los comentarios en audio del DVD del film, lo llega a comparar con una situación reciente: "como una familia de hace diez años, aceptando al gay". 
JAMES, Henry, Las bostonianas (trad. de Sergio Pitol), Barcelona, Mondadori, 2006.

LLOYD, Trevor, Las sufragistas. La valoración social de la mujer, Barcelona, Nauta, 1970.

LONG, Robert Emmet, "Dramatizing James: The Bostonians as a film", Henry James Review, 6.1 (1984) pp. 75-77.

James Ivory in conservation. How Merchant Ivory makes its movies, Ewing, University of California Press, 2005.

MORRA, Irene, "Performing the Edwardian ideal: David Mamet and The Winslow boy", Modern drama, 48:4 (2005), pp. 744-757.

PERSON, Leland S., "Still me(n): Superman meets The Bostonians", en Susan M. Griffin (ed.), Henry James goes to the movies, Lexington, University of Kentucky Press, 2001, pp. 99124.

PETTY, Leslie, Romancing the vote. Feminist activism in American Fiction, 1870-1920, Athens, University of Georgia Press, 2006.

RATTIGAN, Terence, The Winslow boy, Essex, Longman, 1991.

ROSSI, John, "The Archer-Shee case: the root of Terence Rattigan's The Winslow boy", Contemporary Review, 278 (2001), pp. 220-224.

SORENSEN, Sue, "Damnable Feminization?: The Merchant Ivory Film Adaptation of Henry James's The Bostonians", Literature/Film Quaterly, 25.3 (1997), pp. 231-235. 